\title{
APLICABILIDADE DA NORMA NBR ISO 20.121, DE 2012 NOS EVENTOS PRODUZIDOS EM SÃO LUÍS/MA (BRASIL)
}

\section{APPLICABILITY OF NBR ISO 20.121 NORM, OF 2012 IN THE EVENTS PERFORMED IN SÃO LUÍS/MA (BRAZIL)}

Heloísa Alves de Moraes ${ }^{1}$, Osman José de Aguiar Gerude Neto ${ }^{2}$, Tatiana Cristina Santos de Castro ${ }^{3}$

RESUMO: O objetivo deste trabalho é analisar se os eventos dos mais variados portes em São Luís/MA fazem a aplicação da norma NBR ISO 20.121 de 2012, a qual estabelece critérios para eventos sustentáveis, e se os envolvidos nesse processo (produtores e funcionários em geral) têm consciência de suas atitudes para com meio ambiente. Esta pesquisa tem caráter exploratório, com procedimentos técnicos de pesquisa bibliográfica e pesquisa de campo, onde foram realizadas visitas e aplicação de questionários semiestruturados com doze produtores e casas de eventos do município de São Luís - MA. Sendo assim, pôde ser constatado que a norma de evento sustentável é desconhecida por produtores e casas de eventos do município de São Luís - MA, refletindo a triste realidade, do estado e do país, onde a geração de lucro e utilização dos recursos naturais de forma irresponsável visa apenas à ascensão econômica, sem se preocupar com os impactos ambientais gerados.

PALAVRAS-CHAVE: Impactos ambientais. Produtores. Sustentável.

ABSTRACT: The goal of this paper is to analyze whether the events of all sizes in Sao Luís - MA, make the application of the standard ISO 20121 of 2012, which establishes criteria for sustainable events, and whether those involved in this process (producers and employees in general) are aware of their attitudes towards the environment. This research is exploratory, with technical procedures for bibliographic inquiry, field research, where it was performed visits, and application of semistructured questionnaires among twelve producers and event houses in the municipality of the São Luís city - MA. Thus, it could be seen that the sustainable event standard is unknown to producers and event houses of the São Luís city - MA, reflecting the sad reality of the state and the country where the profit making and use of the natural resources irresponsibly aim oulyat the economic rise without worrying about environmental impacts.

KEYWORDS: Environmental Impacts. Producers. Sustainability

\footnotetext{
${ }^{1}$ Graduanda em Engenharia Ambiental na Universidade CEUMA. E-mail: heloisaalves@ gmail.com

${ }^{2}$ Mestre em Ciências da Animal/UEMA. Coordenador do Curso Superior de Tecnologia em Gestão Ambiental da Universidade CEUMA. E-mail: osmangerude@ hotmail.com

3 Mestre em Sustentabilidade de Ecossistemas/UFMA. Professora do Instituto Federal do Maranhão/IFMA. E-mail: tatiana.castro21@ @otmail.com
} 


\section{INTRODUÇÃO}

Em decorrência dos eventos, independentemente de sua proporção, são associados problemas ambientais, gerando vários impactos ao meio ambiente. A concepção do evento, os recursos, materiais utilizados e a logística geram efluentes responsáveis por várias alterações nos meios físico, biótico e socioeconômico. Como por exemplo, os resíduos gerados pela poluição sonora, desperdícios de recursos naturais, impulsionando consequências negativas para qualidade de vida.

Os eventos são encontros planejados que precisam de espaço e tempo para que aconteçam, proporcionam experiências e/ou transmitem conhecimento. Concentram pessoas nos mais diversos lugares e com inúmeras finalidades e são essenciais para todos se socializarem, porém tais situações geram impactos sociais, ambientais e econômicos, exatamente nos fundamentos do tripé da sustentabilidade. (ABNT NBR ISO 20.121, 2012).

Devido a este potencial poluidor, estão sendo criados mecanismos que possam auxiliar no equilíbrio, tanto nas esferas ambientais, quanto econômicas e sociais, para enquadrar os eventos dentro do conceito de sustentabilidade (MOURA, 2008). ABNT NBR ISO 20.121 de 2012 é mais um instrumento de gestão que possibilita a tentativa de inserir medidas que visem amenizar os impactos causados pelos eventos, sendo este um sistema de gestão voltado para amparar os preceitos da sustentabilidade, abordando todos os seus eixos. De acordo com a publicação: “[...] Esta norma é para ser aplicada de forma flexível e permitirá que as organizações que não trabalhem em prol do desenvolvimento sustentável, comecem a implantar um sistema de gestão para sustentabilidade de eventos (...)" (ABNT NBR ISO 20.121, 2012).

Esta recomenda e estabelece um sistema de gestão para que seja implantado e aperfeiçoado no decorrer do tempo, garantindo conformidades com as políticas do desenvolvimento sustentável. É preciso determinar o escopo, identificar e engajar os interessados, definir os princípios que regerão o desenvolvimento sustentável, documentar todo o processo, designar funções e assegurar a comunicação e, ainda, identificar e avaliar as questões incluindo as ambientais, sociais e econômicas, como também promover recursos para conscientização e o monitoramento para avaliação do desempenho e, por fim, tentar melhorá-lo, caso for necessário.

Devido ao desconhecimento da maioria, tal norma ainda encontra dificuldades para a implementação deste sistema de gestão para sustentabilidade de eventos, no Brasil, onde ainda é muito baixo esse comprometimento e, principalmente, no estado do Maranhão. Alguns megaeventos no país tiveram esse diferencial com ações e resultados benquistos, deixando um 
legado positivo, para os participantes e para as áreas de abrangência. Como exemplo dISO, o Rock in Rio, o primeiro a obter a certificação na América Latina no âmbito da gestão sustentável, considerado o maior evento musical do mundo, o qual utilizou o sistema de gestão que possibilitou potencializar os seus impactos positivos, e minimizando os negativos (ROCK IN RIO, 2016).

O objetivo deste trabalho é analisar se as produtoras e casas de eventos dos mais variados portes em São Luís - MA fazem a aplicação da norma NBR ISO 20.121 de 2012 em seus eventos, e se os envolvidos nesse processo (produtores e funcionários em geral) tem consciência de suas atitudes para com meio ambiente.

\section{MATERIAIS E MÉTODOS}

Esta pesquisa tem caráter exploratório no que diz respeito às produtoras e casas de eventos de São Luís - MA, e do ponto de vista dos procedimentos técnicos adotados, pode-se classificá-la como pesquisa bibliográfica e pesquisa de campo, sendo os objetivos podendo ser alcançados mediante a realização dos métodos relatados a seguir.

Foram realizadas visitas aos empreendimentos localizados no centro histórico da cidade e na área nobre, como Lagoa da Jansen, e parte da Avenida Litorânea do município de São Luís. Foram questionados ainda 4 produtores de eventos independentes, sem locais fixos, onde foram observados sua abrangência, quantidade de funcionários, efluentes e resíduos gerados, preocupação em relação a poluição sonora e conhecimento e aplicabilidade na norma NBR ISO 20.121 de 2012.

Foram aplicados o questionário técnico com os responsáveis por essas empresas, com o intuito de avaliar qual a relação destas com o meio ambiente e se estes empresários se preocupam com as questões sustentáveis quando da realização de seus eventos. Ao todo, foram 12 questionários aplicados, além dos 4 produtores independentes, duas casas de eventos da Av. Litorânea, uma casa de show na Lagoa da Jansen e um arraial na Cohama. No centro histórico de São Luís, foi aplicado o questionário em um evento de caráter religioso que ocorreu na praça Maria Aragão e os outros 3 foram aplicados em espaços de entretenimento no Reviver.

O questionário levou em consideração os últimos eventos realizados em suas três etapas: a preparação e organização do evento, o evento e o pós evento. Foi subdividido em três partes: na primeira parte denominada, Evento, aborda o porte do evento, a localização, frequência, números de funcionários e a capacidade de lotação; na segunda parte, "Evento e a ABNT NBR ISO 20.121", trata os requisitos com orientações de uso da normativa para conhecer qual a relação entre a alta 
direção e produção do evento quanto ao conhecimento da Norma e como funciona a gestão dos aspectos ambientais, se há preocupação com toda a cadeia produtiva e parceiros envolvidos.

A parte III, de Mitigação de impactos, tem como objetivo verificar se existe algum tipo de reutilização, redução e reciclagem no processo dos materiais e recursos utilizados no evento e se existe o controle e monitoramento dos impactos causados e se estes se interessam pela possibilidade da implantação do sistema de gestão para a sustentabilidade de eventos, assim como se a questão de uma certificação ambiental tem um custo benefício atrativo.

\section{RESULTADOS E DISCUSSÕES}

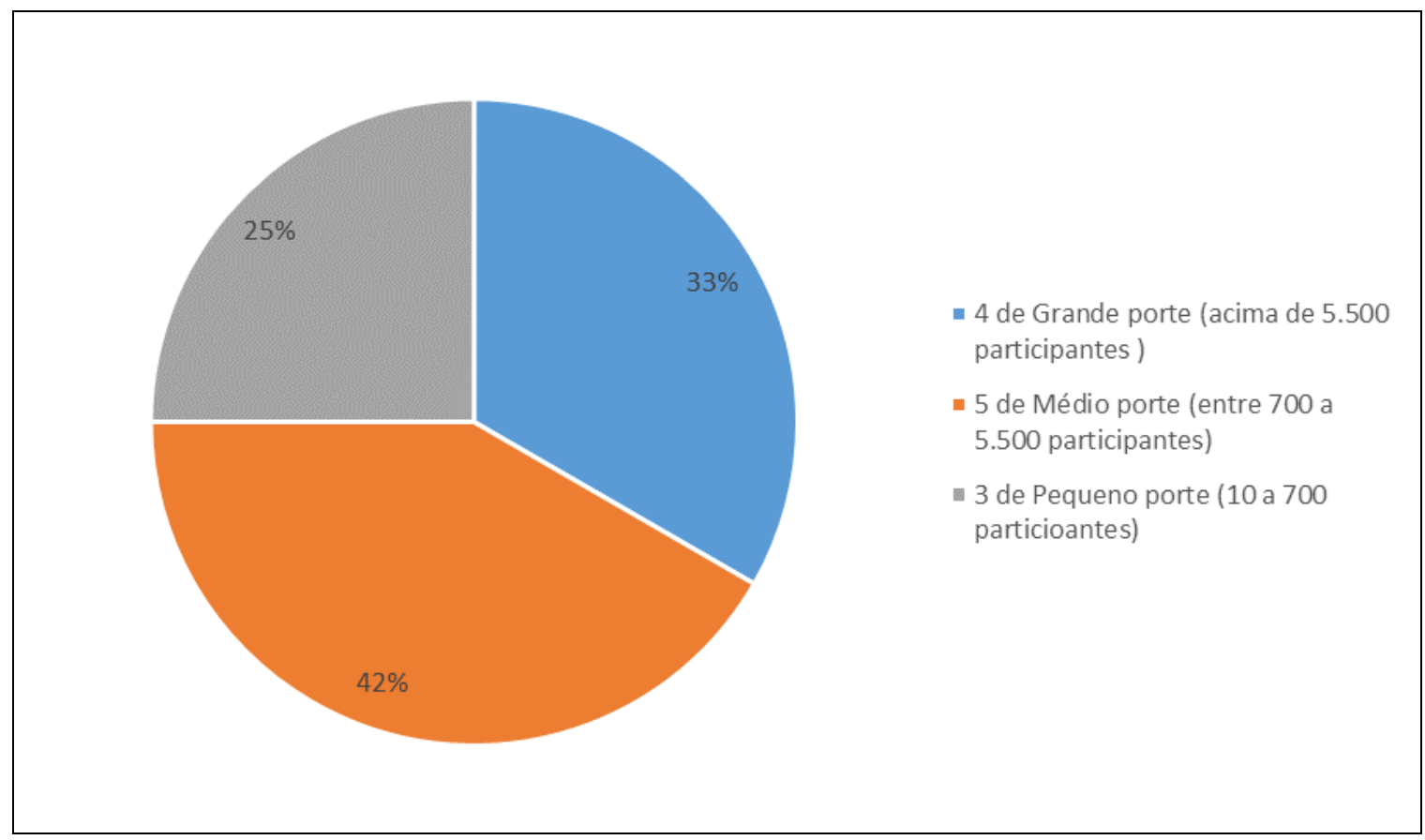

Gráfico 1: Número total de eventos estudados na pesquisa e seus respectivos portes.

A aplicação do questionário demonstrou que, dos doze entrevistados, nenhum conhece de fato a norma ABNT NBR ISO 20.121 de 2012. Foram entrevistados 4 eventos de grande porte (acima de 5500 participantes), 5 de médio porte (entre 700 e 5500 participantes) e 3 de pequeno porte (entre 10 e 700 participantes). Destes apenas dois organizadores já ouviram falar da Norma, mas não se aprofundaram em obter mais conhecimento, sendo este um produtor independente de evento de médio porte e outro de uma casa de evento de pequeno porte no Centro Histórico no município de São Luís - MA. Cabe ressaltar que somente 2 entrevistados possuem a Licença Ambiental para operação, o que comprova a falta de interesse dos produtores e a falta de fiscalização do munícipio. 
Quadro 1 - Conhecimento da norma NBR ISO 20.121, 2012 pelos produtores de São Luís - MA.

\begin{tabular}{|c|c|c|c|}
\hline \multirow{3}{*}{ Variáveis pesquisadas } & \multicolumn{3}{|c|}{ Porte dos Eventos } \\
\hline & Grande & Médio & Pequeno \\
\hline & \multicolumn{3}{|c|}{ Respostas Positivas } \\
\hline Conhece a norma NBR ISO 20.121? & 2 & 0 & 0 \\
\hline Interessa-se por possuir selo de empresa sustentável? & 4 & 5 & 3 \\
\hline $\begin{array}{c}\text { Conhece as vantagens da implantação de um sistema } \\
\text { de gestão de eventos sustentáveis com a relação } \\
\text { custo x benefício? }\end{array}$ & 4 & 5 & 2 \\
\hline $\begin{array}{l}\text { Busca parceiros comprometidos com o meio } \\
\text { ambiente? }\end{array}$ & 3 & 3 & 2 \\
\hline
\end{tabular}

Fonte: Autores, 2016

Em relação aos empresários levarem em consideração se seus parceiros se preocupam com a sustentabilidade, 8 afirmaram que sim, enquanto os outros 4 gostariam de ter esta parceria, mas não têm conhecimento, porém afirmaram que ISO pode influenciar de forma positiva na imagem de si mesmos perante a sociedade. Esta resposta demonstra uma atitude válida na busca do desenvolvimento sustentável, corroborando com as ideias expressas por Cury (2012), o qual afirma que a educação ambiental e o desenvolvimento sustentável devem partir de todos os setores da sociedade, e que as empresas certificadas têm uma condição de se sobressair no mercado perante suas concorrentes.

Para que esses preceitos acima citados sejam postos em prática, a empresa precisa de um Sistema de Gestão Ambiental - SGA para seus resíduos. Segundo Andrade (2006), um sistema de gestão ambiental completo é aquele que se preocupa desde a extração dos recursos naturais até a destinação final dos efluentes gerados. Desta forma, 7 dos produtores (eventos) entrevistados não possuem sistema de gestão qualquer, mas demonstraram interesse pela possibilidade de implementá-lo; 2 afirmaram possuir o sistema de gestão, o qual não engloba as questões ambientais apenas a logística do empreendimento, e somente três responderam existir um sistema de gestão que se preocupa em mitigar os impactos causados, mas de forma arbitrária, e longe dos preceitos necessários para satisfazer a Norma.

Para a variável "resíduos sólidos", somente 2 possuem sistema de coleta seletiva, 6 responderam que existe preocupação com os resíduos sólidos, mas não possuem coleta seletiva, e os 
4 restantes, o lixo é apenas recolhido pela prefeitura, ou seja, é preciso trabalhar mais as possibilidades para um melhor descarte e aproveitamento deste material, que beneficie tanto o empreendimento quanto a sociedade. Esta realidade não é só de eventos produzidos no município de São Luís - MA, já que a maioria dos empresários e a população em geral no Brasil não se preocupa em fazer a separação dos resíduos produzidos em seus estabelecimentos e uma das formas de modificar esta realidade é através da educação ambiental, a qual é capaz de criar uma conscientização de importância entre a sociedade e o meio ambiente em que habita (BRASIL, 2005).

Relacionado a casa de evento e os produtores, quanto à preocupação com meio ambiente, e se ISO pode ser percebido pelos clientes: 6 dos entrevistados acreditam que sim, 5 acreditam que não, e somente 1 acha que talvez essa relação possa ser percebida pelos clientes. Este resultado já é mais animador, pois demonstra que é importante para o produtor e/ou casa de evento essa relação com o meio ambiente para o público, causando um impacto positivo para ambos.

Quadro 2 - Gestão e mitigação dos impactos causados pelos eventos participantes da pesquisa em São Luís - MA.

\begin{tabular}{|c|c|c|c|}
\hline \multirow{3}{*}{ Variáveis pesquisadas } & \multicolumn{3}{|c|}{ Porte dos Eventos } \\
\hline & Grande & Médio & Pequeno \\
\hline & \multicolumn{3}{|c|}{ Respostas Positivas } \\
\hline Possui sistema de gestão? & 3 & 1 & 1 \\
\hline $\begin{array}{l}\text { Possui coleta seletiva antes, durante ou após a } \\
\text { realização do evento? }\end{array}$ & 1 & 1 & 0 \\
\hline $\begin{array}{c}\text { Existe algum tipo de precaução com os resíduos } \\
\text { orgânicos gerados? }\end{array}$ & 0 & 0 & 0 \\
\hline $\begin{array}{l}\text { Aplica algum tipo de tratamento de efluente antes, } \\
\text { durante ou após a realização do evento? }\end{array}$ & 3 & 1 & 1 \\
\hline $\begin{array}{l}\text { Utiliza material reciclado para confecção do seu } \\
\text { evento? }\end{array}$ & 2 & 4 & 2 \\
\hline Algum tipo de preocupação com a poluição sonora? & 3 & 4 & 2 \\
\hline $\begin{array}{l}\text { Aplica algum tipo de monitoramento dos impactos } \\
\text { causados pelo evento? }\end{array}$ & 1 & 1 & 0 \\
\hline É capaz de quantificar o volume de resíduo gerado? & 0 & 1 & 1 \\
\hline Possui alguma ação de compensação ambiental? & 0 & 0 & 0 \\
\hline
\end{tabular}




\begin{tabular}{|c|c|c|c|}
\hline $\begin{array}{c}\text { Aplica alguma medida de redução de consumo de } \\
\text { água e energia na realização dos eventos? }\end{array}$ & 1 & 5 & 1 \\
\hline $\begin{array}{c}\text { Faz algum tipo de trabalho de conscientização } \\
\text { ambiental com os funcionários? }\end{array}$ & 0 & 2 & 1 \\
\hline $\begin{array}{c}\text { Percebe algum tipo de cobrança ou preocupação com } \\
\text { o meio ambiente por parte dos clientes? }\end{array}$ & 1 & 4 & 2 \\
\hline Existe Licenciamento Ambiental? & 0 & 1 & 1 \\
\hline
\end{tabular}

Fonte: Autores, 2016

Para os resíduos orgânicos nenhuma resposta foi positiva para o manejo destes, não tendo nenhum tratamento diferencial dos outros resíduos. E quanto aos efluentes líquidos, 5 dos entrevistados possuem algum tipo de tratamento dos efluentes, enquanto a maioria não possui. Necessitando, assim, da aplicabilidade de processos que permitam um tratamento adequado para estes resíduos produzidos pelos estabelecimentos. Os resíduos orgânicos podem ser reaproveitados: além da compostagem, servem também para a produção de energia, entre outros programas que podem ser criados para beneficiar a sociedade.

A reutilização ou reciclagem dos materiais usados nos eventos acontecem sempre que possível em 7 dos entrevistados: 4 afirmaram que raramente utilizam dessa prática e 1 que não o faz. Com relação à poluição sonora, 9 afirmam a existência de precauções para este impacto, e 3 estabelecimentos já sofreram modificações físicas para amenizar os efeitos causados pelo som, e somente 3 não têm essa preocupação, incluindo um que não tem conhecimento nenhum sobre o assunto.

Se existe monitoramento e controle dos impactos causados, 6 afirmaram não ter esse tipo de serviço, 1 acredita não ser necessário, 2 afirmam que existe este controle e 3 fazem monitoramento e controle só de um determinado impacto (impacto sonoro). Outro aspecto falho com relação à Norma.

Se o produtor ou casa se interessa em ter um evento com o selo de sustentável em sua empresa, os 12, correspondente aos $100 \%$, tiveram resposta positiva, provando que um certificado de sustentabilidade faz toda a diferença no mercado, trazendo inúmeros benefícios a todos.

De forma geral, ainda existe uma grande deficiência na gestão ambiental voltada para os produtores e casas de eventos, somente 2 são capazes de quantificar seus resíduos gerados. E nenhum possui ações de compensação ambiental, mas 10 destes gostariam de implantar essa prática em suas atividades e somente 2 afirmam ser desnecessário este tipo de procedimento. 
$\mathrm{Na}$ opinião dos entrevistados sobre o custo e benefício de se implantar um sistema de gestão sustentável ser positivo, 2 afirmaram que sim; 9 acreditam que sim, mas a longo prazo e somente 1 produtor acredita gerar só custos. Isto demonstra uma oportunidade para os profissionais das áreas correlacionadas desenvolverem sistemas de gestão sustentáveis para eventos de qualquer gênero.

Os entrevistados foram questionados se utilizam medidas ou mecanismos para reduzir o consumo de água e energia nos eventos. Destes 7 afirmaram que sim, tanto para água quanto energia. Um produtor afirmou somente para energia e 4 não utilizam nenhuma medida ou mecanismo para reduzir o consumo destes.

Na questão da conscientização de seus funcionários em relação ao meio ambiente, somente 3 fazem esse trabalho, enquanto a grande maioria não tem essa preocupação, deixando evidente que os eventos ainda precisam rever seus conceitos com relação ao meio ambiente, inclusive com a necessidade de obtenção da Licença Ambiental.

O que fica claro é que existe uma grande lacuna entre os eventos e a sustentabilidade, pois muitos estão apenas preocupados com os lucros e se esquecem da importância do equilíbrio entre o social, econômico e meio ambiente, e não utilizam desses momentos e espaço para ajudar a conscientizar seus funcionários e clientes.

\section{CONCLUSÕES}

As emergentes questões ambientais em busca do desenvolvimento sustentável ainda precisam ser potencializadas. A falta de conhecimento das normas referentes a suas atividades, aliada à falta de consciência ambiental dos gestores desses empreendimentos no município de São Luís - MA reflete a realidade do estado e do país, ou onde a geração de lucro e utilização dos recursos de forma irresponsável visa apenas a ascensão econômica, sem se preocupar com os impactos ambientais gerados.

Para que este quadro se reverta, é necessário mais comprometimento dos envolvidos no processo e a melhor divulgação e uma maior aplicabilidade das normas em vigor. A educação ambiental é uma ferramenta crucial nesta etapa, assim buscando a conscientização dos envolvidos nestas atividades, para a necessidade de conservação de um meio ambiente equilibrado. 


\section{REFERÊNCIAS}

ABNT NBR ISO 20121. Sistemas de gestão para sustentabilidade de eventos - Requisitos com orientações de uso. 2012

ANDRADE, R. O. B.; TACHIZAWA, T. e CARVALHO, A. B. Gestão Ambiental - 2.ed. São Paulo, Editora Pearson, 2006. 172 p.

BRASIL, Diretoria da Educação Ambiental. Programa Nacional de Educação Ambiental ProNEA. Brasília: MMA, 2005.

CURY, D. Gestão da qualidade: educação ambiental, auditoria e certificação ambiental - 1.ed. São Paulo, Editora Pearson, 2012. 342 p.

MOURA, L. A. A. Qualidade e Gestão ambiental: sustentabilidade e implantação da ISO 14.001. São Paulo, Editora Juarez Oliveira, 2008.

ROCK IN RIO. Disponível em: http://rockinrio.com/rio/pt-BR/por-um-mundo-melhor. Acesso em 20 de maio de 2016. 